\title{
PerCursos
}

\section{Pode a mulher artista falar? A experiência de Helena Almeida a partir da série Ouve-me (1978-80)}

\begin{abstract}
Resumo
O artigo tem como objetivo, a partir de uma reflexão teórica que aproxima feminismo e marxismo, o estudo de alguns trabalhos da série “Ouve-me", da artista portuguesa Helena Almeida (1934-2018). Para tanto, as categorias analíticas de gênero (LAURETIS, 1987), ideologia (HADJINICOLAOU, 1980) e experiência (SPIVAK, 2010) são mobilizadas na análise dos caminhos percorrido pela artista, durante as décadas de 60 e 70. Através de sua prática artística, em que o corpo é elemento chave, observa, pensa, regista e critica o meio social e cultural no qual esteve inserida.
\end{abstract}

Palavras-chave: feminismo; Helena Almeida; gênero; ideologia.
Vera Rozane Araújo Aguiar Filha

Mestre em História pela

Universidade Federal de São

Paulo - UNIFESP. Doutoranda em

Arte Contemporânea na

Universidade de Coimbra, Portugal.

Brasil

verinha.arauj025@gmail.com orcid.org/0000-0002-6951-2595

\section{Para citar este artigo:}

ARAÚJO, Vera Rozane A. F. Pode a mulher artista falar? A experiência de Helena Almeida a partir da série Ouve-me (1978-80). PerCursos, Florianópolis, v. 22, n.50, p. 197 - 214, set./dez. 2021. 


\title{
Can the female artist speak? Helena Almeida's experience by the Listen to me series
}

\section{(1978-1980)}

\begin{abstract}
This article some works in the series "Listen to me" by the Portuguese artist Helena Almeida (1934-2018), based on a theoretical reflection that brings together feminism and Marxism. Therefore, the analytical categories of gender (LAURETIS, 1987), ideology (HADJINICOLAOU, 1980), and experience (SPIVAK, 2010) are mobilized in the analysis of the paths taken by the artist during the 6os and 70s. Through her artistic practice, in which the body is a key element, she observes, thinks, registers and criticizes the social and cultural environment to which it was inserted.
\end{abstract}

Keywords: feminism; Helena Almeida; gender; ideology. 
"Why Have There Been No Great Women Artists", de Linda Nochlin (1971), tem sido mote fundamental para a teoria e história da arte feminista, redimensionando e até mesmo inserindo a participação das mulheres no campo da arte, não só no que se refere à prática, bem como da escrita e da crítica. Salvaguardando os limites da tradução e o falso dilema entre a colocação artistas mulheres ou mulheres artistas, ${ }^{2}$ o texto da historiadora traz a seguinte pergunta: por qual razão ainda não houve notáveis artistas mulheres? Apesar de ter uma construção demasiada simplificada, coloco a mesma pergunta dita de outro modo: Afinal, como, historicamente, não se convencionou atribuir às mulheres a posição de grandes artistas?

Para nós que estudamos o feminismo, a resposta é imediata. Entretanto, a estrutura patriarcal opressora e misógina, que, ao longo do tempo, retira das mulheres qualquer protagonismo em níveis sociais, culturais e econômicos, vem sendo descortinada, ainda que em passos lentos. Mesmo dentro do meio acadêmico, a consciência dos paradoxos que envolvem as questões de gênero não é consenso, até para aqueles inseridos nas Ciências Humanas e Sociais. Em níveis políticos, internacionalmente, acompanha-se a emergência de uma onda conservadora de extremadireita, sobretudo, no que concerne termos morais e ideológicos. Essas ideias têm sido pano de fundo de diversos conflitos e de justificativa para regimes de exceção ao longo do século XX e XXI. A arte (não só aquela praticada por mulheres), em contextos de predominância do conservadorismo, sofre e é questionada.

A experiência de mulheres artistas como forma de resistência a esses vetores me parece ainda mais combativa e expressiva. Entretanto, outro problema surge, uma vez que a arte como exercício do pensamento não estaria delegada às mulheres. Ora, as suas práticas não foram reconhecidas pela História da Arte por muito tempo. A luta (inconsciente e consciente) para a inserção no campo, como já apontava Virgínia Woolf em “A room of One’s Own”, publicado originalmente em $1928^{3}$, é histórica, uma vez que

\footnotetext{
${ }^{1}$ Em 1971, Linda Nochlin publicou “Why are there no great Women Artist?" em Woman in Sexist Society: Studies in Power and Powerlessness. O ensaio foi revisado e publicado na Revista ArtNews sob o título: "Why Have There Been No Great Women Artists?".

${ }^{2}$ Tradução para o português brasileiro utilizou mulheres artistas. Cf. (NOCHLIN, 2016).

${ }^{3}$ Virgínia Woolf, já na primeira metade do século $X X$, trouxe à tona questões referentes às assimetrias dos papéis sociais entre os gêneros, problematizando, como, historicamente, as mulheres foram
} 
as mulheres estiveram sempre numa posição de desfavorecimento social e principalmente, econômico, fato que contribuiu para sua falta de oportunidade para vivências no campo das artes, por exemplo. Não havia um lugar onde as mulheres pudessem dar vazão ao seu lado criativo e intelectual, pois estavam sempre condenados ao crivo moral que as rebaixava ao papel de filha, esposa, mãe, trabalhadora.

Dito isso, trago a experiência de Helena Almeida, artista plástica portuguesa (19342018), que usou de seu corpo, a partir da linguagem gestual, do pensamento e da escrita, como combate e denúncia para assuntos de diferentes naturezas, tanto do mundo artístico, bem como do mundo social. Teve uma trajetória bastante consistente e versátil. Filha do escultor português Leopoldo de Almeida, aos 21 anos concluiu o curso de Pintura, na Escola Superior de Belas Artes de Lisboa e deu início a sua carreira na década de 1960. Participou, em 1961, da II Exposição de Artes Plásticas da Fundação Calouste Gulbenkian, de onde também foi bolsista em Paris, a partir de 1964. Lá, teve contato com a Abstração. Expôs individualmente pela primeira vez em 1967, na Galeria Buchholz, em Lisboa, com um trabalho bastante crítico, que usou das formas geométricas para questionar o que seria, de fato, o espaço pictórico. Não à toa, o grande slogan da obra de Helena Almeida é “meu corpo, minha obra”, uma vez que entendia seu corpo em íntima relação com o processo criativo, que se configura como objeto vivo de sua prática como artista. De acordo com Rita Mira, foi na década de 1970 que a artista abandonou os métodos mais tradicionais de representação e passou a se dedicar a diferentes experiências nas quais seu corpo era o grande centro da produção e completa:

Normalmente com um vestido preto e largo ou uma bata branca de trabalho, a imagem e o corpo da artista não surgem como autorretrato, tratando-se da própria matéria-prima da obra, uma presença reiterada de si mesma, sem personagens ou artifícios. Helena Almeida utiliza, numa ótica transdisciplinar, a pintura, o desenho, a fotografia, a performance, o vídeo e a escultura, ao longo do seu percurso artístico, consolidado pela autorrepresentação. Se o corpo é o local onde todos os limites se confrontam com a existência humana, é também no ponto de vista da sua obra, o limite das diversas disciplinas artísticas. (MIRA, 2015, pp. 221222) 
Helena Almeida explorou o campo da arte conceitual e até sua morte tratou de maneira singular as tensões entre ideia-corpo-materialidade-obra. Dito isso, neste trabalho, realizo estudo acerca da trajetória de um capítulo importante da história da arte de Portugal. Para tanto, proponho a aproximação entre interpretações marxistas e feministas para pensar a experiência dessa mulher. As categorias analíticas de género (LAURETIS, 1987), ideologia (HADJINICOLAOU, 1980) e experiência (SPIVAK, 2010) são mobilizadas na reflexão. Os cruzamentos desses conceitos são ferramentas para abalar uma estrutura dominante no campo da historiografia e da teoria da arte que não dá o devido valor à participação das mulheres.

\section{Alguns aprofundamentos teóricos e metodológicos}

\section{1) Marxismo e o conceito de ideologia da e para as imagens:}

“Toda história da sociedade é a história da luta de classe”, já diziam Marx e Engels, em seu "Manifesto do Partido Comunista” (MARX; ENGELS, 2001). Tratando-se do mundo das imagens, a afirmação também é plausível. Conforme apontou o historiador da arte Nicos Hadjinicolaou, uma vez que a história das ideologias estéticas é uma história particular da história geral da luta de classe, a história da sucessão de lutas entre diferentes ideologias estéticas, é, em última instância, determinada pela luta econômica de classe.

Partindo dessas premissas, é fundamental pensar a produção de imagens como uma prática de classe, que, independente de sua qualidade, é uma obra ideológica. A ideologia, grosso modo, consiste num conjunto de coerências relativas às representações, valores e crenças originados nas relações dos agentes históricos com "seu mundo". São muitas as ideologias: moral, religiosa, política, filosófica e também, estética. No que se refere à ideologia dominante, é suposto refletir como esta acaba por controlar as variadas ideologias que conformam a vida social, a fim de atingir certa manutenção dos paradigmas daqueles que detêm o poder (no caso das sociedades capitalistas, estamos a falar do poder econômico e político). 
Assim, surge a seguinte questão: qual ideologia estética a ideologia burguesa dominante respalda em perspetiva histórica? A história da arte ocidental é um bom instrumento para obtermos essa resposta. Nicos Hadjinicolaou destaca que a ideologia burguesa da arte esteve e ainda está composta por três principais matrizes analíticas: 1) estudo das artes maiores, quais sejam, pintura, escultura e arquitetura; 2) ideia de genialidade e; 3) atribuição de valores estéticos pré-estabelecidos, como questões formais e de conteúdo - a ideia de cânone, modelo (HADJINICOLAOU, 1980).

O autor propõe um caminho para vencer os obstáculos que a ideologia burguesa impõe para a conformação de uma narrativa para a História da Arte. O primeiro obstáculo é a tendência que pensa a história da arte como a história dos artistas; o segundo, cuja análise ganha aspecto mais estruturalista, é a história da arte como a história das civilizações, ou melhor, que pensa a arte como fruto de um espírito de época; e por último, superar o obstáculo da história da arte como a história das próprias obras. A proposta é: afinal, qual o verdadeiro objeto da história da arte? O artista, o contexto ou a obra? Para Hadjinicolaou, o caminho está na ideologia das imagens, ou seja, uma combinação específica de elementos formais e temáticos das imagens que constituem uma das formas particulares da ideologia global de uma classe social.

Para esta análise, ao estudar a prática de Helena Almeida, é interessante pensar nos determinados enquadramentos de sua obra na lógica da ideologia burguesa e também como suas obras escapam disso. Apagamentos e ausências também ocorrem devido à existência de um teto não alcançado. Qual a colocação da artista em torno desses deslocamentos? Isso posto, endosso a seguinte reflexão: no momento em que as trajetórias de artistas e suas obras se inserem na narrativa dominante, os desenrolares são múltiplos. O contrário também é legítimo e precisa ser estudado.

\section{2) A categoria género:}

Teresa de Lauretis, em seu ensaio “Tecnologia de Género" (1987) considera que o conceito de gênero como diferença sexual tem servido de base para as intervenções feministas, nos campos epistemológicos e cognitivos. Então, para problematizar o gênero e para reconstruí-lo em oposição aos contratos do patriarcado, devemos nos afastar do 
referencial androcêntrico, em que gênero e sexualidade são (re)produzidos pelo discurso da sexualidade masculina. Todavia, essa ideia limita o pensamento feminista, uma vez que cria categorias essencialistas como "cultura da mulher", "maternidade", "escrita feminina”, “feminilidade” (LAURETIS, 1987).

Assim, o conceito de diferença acaba por cair em duas armadilhas. A primeira, uma vez que direciona o pensamento crítico feminista ao arcabouço conceitual de uma oposição universal do sexo, ou seja, a mulher como o produto da diferença do homem, tornando-se difícil articular as diferenças na combinação mulheres-mulher. A segunda, diz respeito à recuperação do potencial epistemológico do pensamento feminista sem sair da prisão da lógica patriarcal, o que chama de "prisão domiciliar da linguagem", ou seja, a conceção da multiplicidade do sujeito, não apenas limitado pela diferença sexual, mas também de classe e raça, por exemplo.

Teresa de Lauretis nos traz quatro proposições, na tentativa de pensar que apenas negando a diferença sexual e, consequentemente, o gênero, como componente da subjetividade em mulheres reais é que desconstruiremos pensamentos do masculino como universal ou das mulheres como metáforas. Para a autora: 1) gênero é (uma) representação; 2) a representação do gênero é a sua construção; 3) a construção do gênero vem se efetuando em diferentes meios, inclusive onde não se espera que aconteça; 4) e, paradoxalmente, a construção do gênero também se faz por meio da sua desconstrução (LAURETIS, 1987).

Precisamos, segunda a autora, de uma crítica feminista radical aos discursos dominantes sobre o gênero, uma vez que a desconstrução do gênero inevitavelmente causa a sua reconstrução. Assim, o movimento para dentro e fora do gênero como representação ideológica, caracteriza o sujeito do feminismo, num paradoxo entre a representação de gênero e o que essa representação exclui, ou melhor, torna irrepresentável (o que está fora do binarismo). Para o caso de Helena Almeida, percebese uma consciência desses paradoxos, na medida em que a artista tenta diluir qualquer marca de "feminilidade" em suas obras. 
Uma teoria da arte feminista, como em Nochlin, citada no início deste trabalho, tomou como ponto central da discussão os reducionismos no que se refere à experiência das mulheres, tendo o gênero feminino como certo termômetro de suas ações e escolhas criativas, reforçando os estereótipos e metáforas. Às mulheres estavam delegados os assuntos sensíveis, sentimentais, familiares, como uma forma de expurgar suas fragilidades "naturais". Entretanto, segundo a autora:

\begin{abstract}
A pergunta "Por que não houve grandes mulheres artistas?" nos leva à conclusão, até agora, de que a arte não é a atividade livre e autônoma de um indivíduo dotado de qualidades, infuenciado por artistas anteriores e mais vagamente e supercial ainda por "forças sociais", mas sim que a situação total do fazer arte, tanto no desenvolvimento do ar- tista como na natureza e qualidade do trabalho como arte, acontece em um contexto social, são elementos integrais dessa estrutura social e são mediados e determinados por instituições sociais específcas e definidas, sejam elas academias de arte, sistemas de mecenato, mitologias sobre o criador divino, artista como He-man ou como párias sociais. (NOCHLIN, 2016, pp. 23-24)
\end{abstract}

Como será visto adiante, em Helena Almeida e numa geração de mulheres artistas inseridas num contexto de luta feminista (mesmo que não atribuído pelas próprias artistas à época), o grande diferencial, no que se refere às suas práticas, é a tomada de consciência seu lugar social, de sua agência, de seus corpos e como esses corpos ocupam e significam, per si e a partir de.

\title{
3) O marxismo, feminismo e a História da Arte:
}

A historiadora da arte Griselda Pollock oferece alguns elementos para refletir sobre o feminismo, a prática das artistas mulheres e a História da Arte, explorando as relações entre elas e o marxismo. De saída, a autora chama atenção para a importância de problematizar uma noção unitária e homogênea de narrativa histórica sobre a arte, apontando como um olhar que leva em consideração as diversas experiências artísticas, não somente a lógica burguesa patriarcal, possibilita a escrita de "novas histórias da arte", com novos olhares e questionamentos. Segundo Pollock: 
A pluralização da história da arte é especialmente significativa, uma vez que abre o campo da interpretação histórica além de uma tradição seletiva, A História da Arte, uma versão canônica disfarçada de única história da arte. Em quem as histórias são contadas, quais interesses? Quais histórias precisaremos encontrar? Como lemos de forma diferente? (POLLOCK, 2008, p. xviii)

Discutir a atuação de mulheres artistas em regimes autoritários, por exemplo, implica em compreender a arte como expressão política, tanto quanto estética, resistência cotidiana a diferentes formas de opressão (estruturais e conjunturais). Também dialogando com a proposta de Pollock, explorar uma "história social da arte", a qual, "informada por uma análise marxista da sociedade - constitui radicalmente um novo corpo de trabalho sobre história da arte que contesta a hegemonia da história da arte modernista burguesa" (POLLOCK, 2008, p. 26-27).

No caso da História da Arte como disciplina, o grande desafio é desnaturalizar toda uma estrutura de pensamento ocidental e consequentemente, burguesa, que olha para os fatos históricos que dizem respeito à arte e aos artistas sob uma ótica pré-construída, como viu-se na análise de Nicos Hadjinicolaou. O combate deve ser contra os conceitos normais do que é arte, do que é ser artista, contra a ideia de genialidade, contra as narrativas contadas por homens sobre outros "grandes homens". Suplantar esses essencialismos (que são, sobretudo, machistas) é uma máxima. Fugir das estruturas dominantes que sempre privilegiaram a ação masculina, no que diz respeito à própria construção do sistema da arte ${ }^{4}$. Apropriando-me das considerações de Walter Benjamim, em sua sétima tese sobre a história, devemos escovar a história (da arte) a contrapelo (BENJAMIN, 1987).

\footnotetext{
4 “'A possibilidade de existência de um 'sistema de arte', reconhecível em sua dinâmica própria, tem sua história: subentende a laicização da cultura legitimada pelo enciclopedismo iluminista e, em consequência, a crescente autonomia da arte com relação à instituição religiosa e política. Ao inventariar e a sistematizar todos saberes e práticas segundo o critério de razão laico, a enciclopédia separa ciências e artes, cada uma delas entre si, e, em simultâneo, reconhece sua afinidade mais ampla enquanto expressões distintas da razão humana" (GUIMARÃES, 2013, p. 2036).
} 


\section{Estudo das experiências}

No clássico “Pode o subalterno falar?”, publicado originalmente em 1985, Gayatri Spivak traz para o centro da reflexão os apagamentos em torno das experiências das mulheres pobres nas narrativas históricas e, consequentemente, na historiografia. Há quem é dado o direito de falar? Falar sobre si e também sobre o outro? Quais narrativas são consideradas relevantes para serem contadas? Quem as escuta?

Para Spivak, o subalterno é caracterizado pelas camadas mais baixas da sociedade e que são constituídas pelos modos específicos de exclusão dos mercados, da representação política e legal e da possibilidade de se tornarem membros plenos no estrato social dominante (SPIVAK, 2010). A esses grupos, a fala está sempre mediada pela voz de outrem, como por exemplo, o meio intelectual, que acaba por reproduzir as estruturas de poder e opressão a partir dessa fala mediadora (SPIVAK, 2010. p. 13). A proposta da autora é imbuir no intelectual pós-colonial certo dever de criar espaços de fala e escuta para que o subalterno possa se articular. No caso estudado por Spivak, sobre o ritual Sati e a prática da autoimolação das mulheres indianas ${ }^{5}$, a necessidade de construir um saber do "sul" demanda a desconstrução do saber hegemônico do "norte", uma vez que só pensamos a partir do que veio antes de nós.

Há diferentes bases teóricas para tratar da questão da mulher, do gênero e da diferença entre mulheres e tudo aquilo que não se enquadra no termo, independente do sexo biológico. Entre a teoria feminista, seja ela moderada, radical, interseccional e, embora, o campo de estudos denominado como "história das mulheres" 6 pareça apologista ao gênero feminino, a necessidade do olhar para essas experiências concretas é relevante e extremamente atual. Não só pelo aumento significativo e notório da

\footnotetext{
${ }^{5} \mathrm{O}$ caso estudado por Spivak trata da violência epistêmica ocidental sobre a cultura das mulheres indianas, que, ao ficarem viúvas, jogavam-se nas piras funerárias dos maridos. Todavia, no período de colonização inglesa, o ritual foi criminalizado (SPIVAK, 2010).

${ }^{6}$ Termo surgiu na França, no contexto da Escola dos Annales, um movimento entre historiadores e historiadoras, durante o século XX, em conformar novos parâmetros para a escrita e apreciação da História enquanto disciplina acadêmica e campo do conhecimento. Já em sua terceira fase, na década de 1970, a publicação da coletânea "Nouvelle Histoire", organizada pelos historiadores Jacques Le Goff e Pierre Nora, foi um divisor de águas, na medida em que traz à baila novos temas, abordagens e problemas para a História. Um capítulo foi dedicado às mulheres, escrito pela historiadora Michelle Perrot, considerada grande referência para o campo de estudos intitulado "História das Mulheres". Sobre o assunto ver: (PERROT, 1995).
} 
atuação delas na política, na economia, na conformação de uma cultura visual compartilhada, por exemplo, mas também pelo desenvolvimento de pesquisas que reposicionam ações femininas no passado, retirando a poeira dessas histórias “esquecidas".

$\mathrm{Na}$ história e na historiografia da arte, é fato que as mulheres foram subalternizadas. No caso de Helena Almeida, mesmo que não tenha sido uma artista esquecida, uma vez que em vida, teve seu devido reconhecimento no cenário artístico português e internacional, é interessante pensar no lugar que esta experiência ocupa na luta pelo direito de fala, no apelo por ser ouvida, por ser agente de sua própria história através de sua arte.

\section{O caso de Helena Almeida}

Helena Almeida foi incansável na busca pela desconstrução do paradigma da pintura como sinônimo do trabalho vinculado à tinta sobre tela. O estatuto pictórico, a partir da materialidade, ou seja, dos meios e das questões formais, foram reflexões caras ao movimento moderno datado dos finais do século XIX e inícios do XX (ARGAN, 2010), que questionou a arte enquanto retrato da natureza. A fim de atingir esse problema, a artista tornou-se a própria tela, num jogo entre a ironia e a crítica. Ela não só se veste de e com a tela, mas dá o pontapé para toda uma trajetória que questionará o estatuto da arte em termos conceituais (natureza vs. forma vs. conceito) e coloca-se no centro da discussão, a partir de seu corpo.

O corpo da mulher sempre esteve presente na arte, entretanto, a geração atuante a partir de 1960, em diferentes contextos, começou a esgarçar esse “uso", num temperamento até então nunca visto na história da arte, conforme aponta Helena Almeida: "A minha obra é o meu corpo, o meu corpo é a minha obra” (ALMEIDA, 2010). A obra passa a ser fruto do gesto, do registo, do toque, da quebra, da rasura, do corte, do visceral, não é apenas representação do corpo ou do meio que ele ocupa.

A artista utilizou a fotografia como recurso para fugir da tela, embora não tenha abandonado a pintura, apenas transformou o suporte. Seus trabalhos são conformados 
de maneira híbrida no sentido material, uma vez que não se reduz à impressão da fotografia. A partir de suas intervenções com a tinta, por exemplo, as obras ganham característica performativa, na medida em que só fazem sentido se interpretadas também através da ação elucidada pelos materiais. Em fins da década de 1970, as imagens de Helena Almeida possuem tom mais dramático, sobretudo nas séries "Ouveme", "Sente-me" e "Vê-me", 1979. As intervenções sobre o corpo da artista aparecem de forma mais explícita, remetem à dor, à angústia, ao desespero. As obras que receberam o título "Ouve-me", entre os anos de 78 e 80, configuram a série que comporta elementos da fotografia e do vídeo.

Os trabalhos estão situados numa fase intermediária da carreira de Helena Almeida. Quase dez anos após Tela rosa para vestir (Imagem 1), num percurso experimental entre corpo e suporte, a artista decide ousar, gritar, denunciar. Um vídeoperformance parte da série "Ouve-me”, datado de 1979 (Imagem 2), é um bom exemplo disso. O corpo aparece velado por uma cortina branca e ao movimentar-se contra essa espécie de parede, a artista se choca, tenta ultrapassar, romper com aquela estrutura que limita da ação. Usa do gesto marcante e seu semblante é de perturbação. A força é elemento preponderante para a narrativa criada por Helena Almeida. A tal parede parece frágil e o expectador vibra ao mínimo movimento que remeta ao rompimento da estrutura, ela força, repete a ação. O aprisionamento aparece como máxima desse trabalho, entretanto, a resistência existe e não deixa de ser uma estratégia que remete às ausências. A artista, a partir de seus movimentos e de seu corpo velado pela fina e sensível cortina, aliado a ausência de sons, confere uma grande força dramática e de apelo. A mulher artista não pode falar, não pode ser ouvida. 
Imagem 1 - Helena Almeida. Tela rosa para vestir, 1969

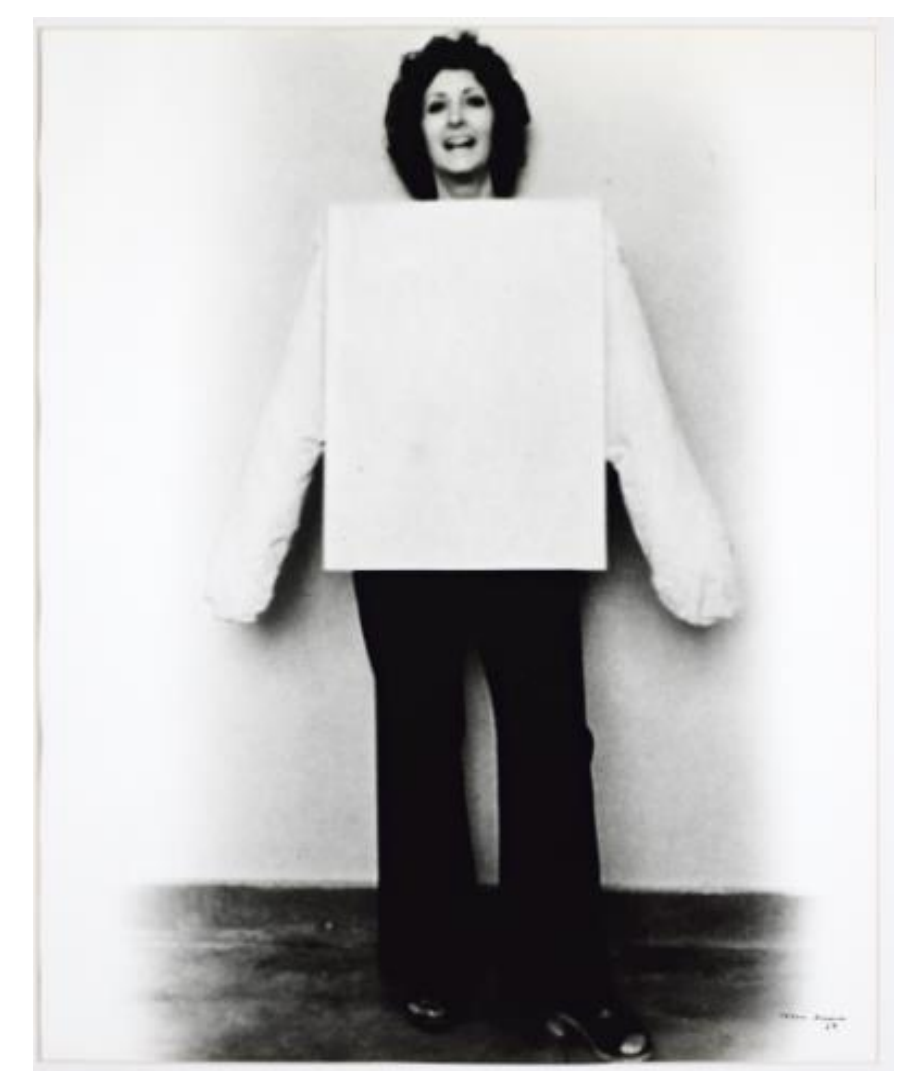

Fonte: (GOMES; RODRIGUES; MENDONÇA, 2006, p. 61).

É interessante pensar, a partir das colocações de Teresa de Lauretis, a necessidade de se perceber suas construções do gênero. Quando me debruço sobre a obra de Helena Almeida, é inevitável pensar que se trata de um corpo de uma mulher, embora a artista tente subverter esta imagem de si: "Eu vejo-me, e vejo os outros colegas meus, sem género feminino ou masculino, ou melhor, vejo-os com uma sensibilidade hermafrodita" (ALMEIDA, 2008). 
Imagem 2 - Helena Almeida. Ouve-me, 1979. VídeoSuper 8, VídeoDVD e VídeoVHS

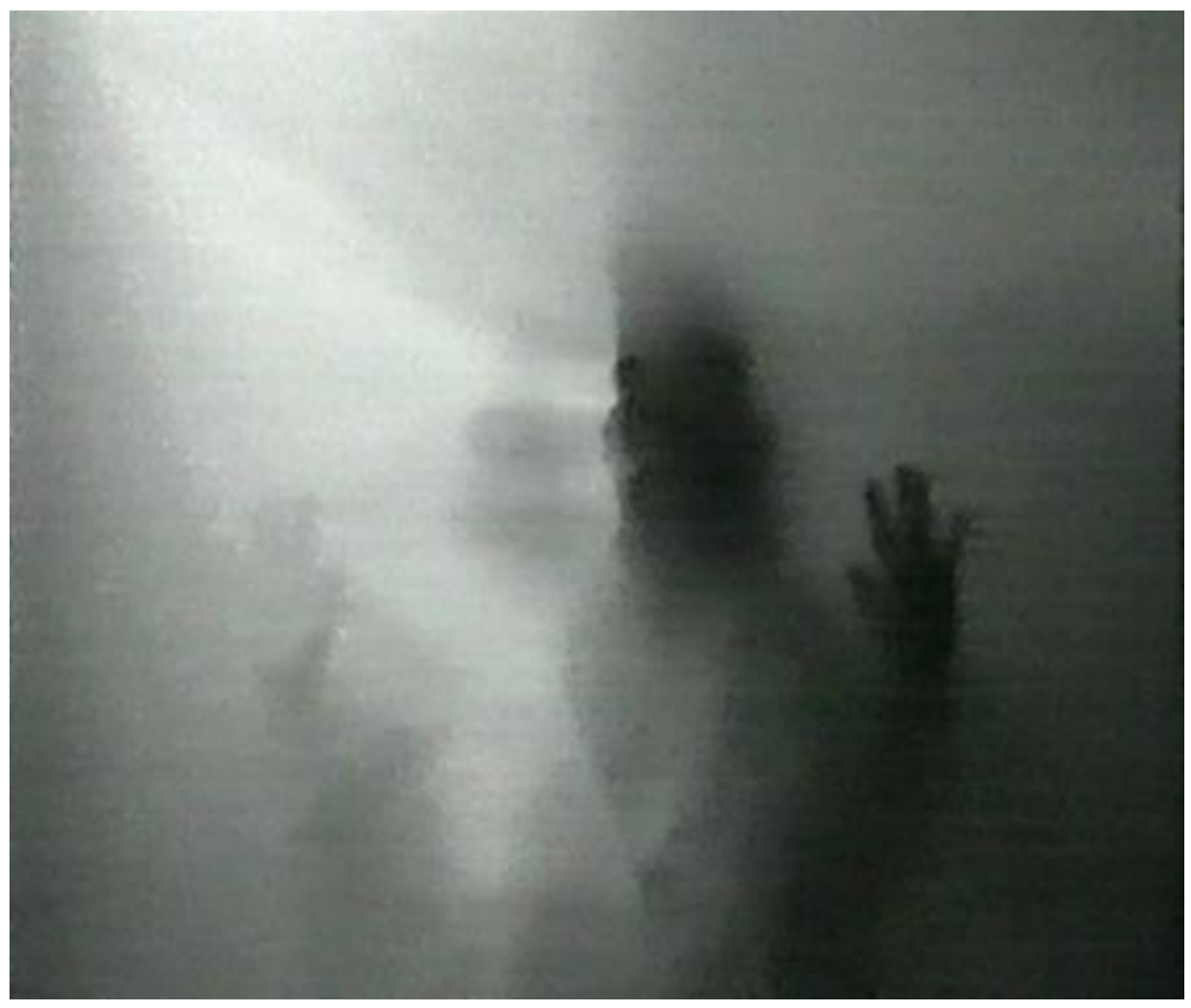

Fonte: Fotografia. Arquivo Pessoal.

Outro aspecto a ser levado em consideração é que Helena Almeida iniciou seu trabalho artístico em finais da década de 60, momento marcante para a história política de Portugal. Em publicação recente, "Portugal sob a égide de ditadura" (2014), a pesquisadora Paula Morais buscou repensar a história de Portugal durante a ditadura Salazarista partindo da análise da palavra escrita como arma disponível em seus sentidos sociais compartilhados e ideológicos. A abordagem da autora é rica quando posta em paralelo com a questão das artes visuais. Sobre o período de Salazar, Morais destaca que em Portugal, durante a primeira metade do século $\mathrm{XX}$, impera a tríade Deus/Pátria/Família, numa espécie de recuperação da ideologia absolutista e completa: “um país agrário, necessitou da instauração de um regime ditatorial para ascender ao patamar ocupado pelos restantes países industrializados" (MORAIS, 2014, p. 25). 
Imagem 3 - Helena Almeida. “Ouve-me”, 1979

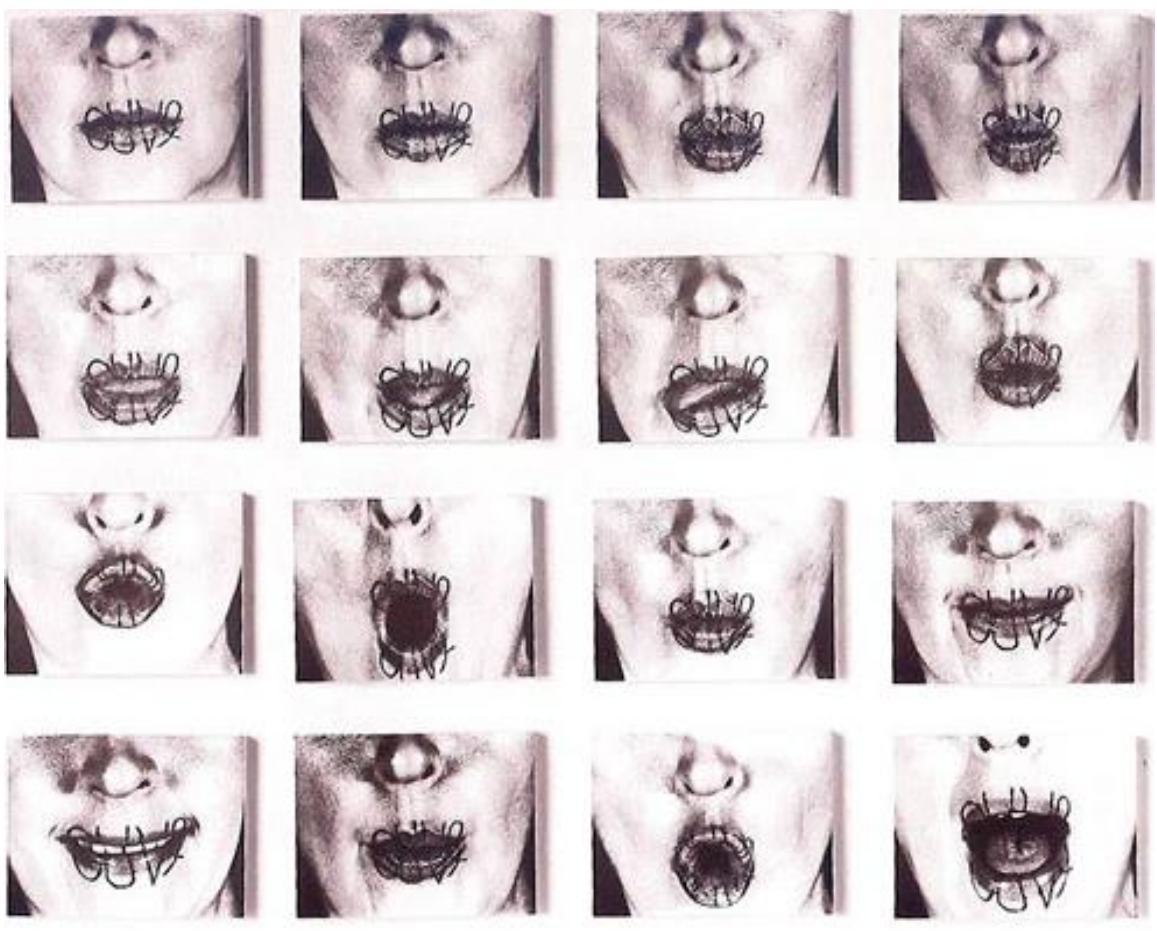

Fonte: (GOMES; RODRIGUES; MENDONÇA, 2006, p. 62).

Nesse sentido, é crucial ter em vista que a instauração do regime ditatorial em Portugal teve a ver com a tentativa de afirmação de uma identidade nacional através do retorno ao passado, a fim de impor uma origem ancestral, oriundos de um universo simbólico construído historicamente, onde o português se distingui dos demais povos. $\mathrm{Na}$ tentativa de implantar algo novo e original, os portugueses acabaram por ficar prisioneiros de seu próprio país: "privilegiava-se a mediocridade e silenciavam-se os opositores com a violência que o Estado impunha como um meio defensivo desse Portugal heroico e destinado a grandes feitos" (MORAIS, 2014. p. 37). Esses meios defensivos eram preservados por mecanismos de controle das massas. Segundo Morais e em diálogo com autores que já se debruçaram sobre o tema, a censura atuou como eficaz silenciadora e manipuladora de opinião, condicionando todas as informações que chegavam à público. Portugal era um país "violentamente silenciado" (OLIVEIRA, 2015, p. 65). 
A boca costurada de Helena Almeida que também compõe a série "Ouve-me" (Imagem 3) traz uma clara denúncia do período em que vivia, quando a arte passou a ser esse instrumento de mediação entre imaginário e realidade, ao trazer assuntos políticos para o campo da representação. Nesse sentido, a arte aliada à ironia e à metáfora, entra em jogo como forma de intervenção, embora sua eficácia contemporaneamente aos acontecimentos não seja instantânea, uma vez que as circulações das obras de Helena Almeida ainda não aconteciam. Somente nas décadas seguintes esses trabalhos começaram a aparecer ao público.

As escolhas concretas para a conformação da História da Arte (em maiúsculo por se tratar da disciplina) atendem a uma estética dominante, ou seja, burguesa. Todavia, a arte praticada por mulheres nas décadas de 1960 e 1970 rompe justamente com a lógica da obra de arte como mercadoria. Ora bem, o que não significa que essas obras não receberiam valor a posteriori, quando legitimadas pelo sistema da arte - que é conformado a partir da lógica burguesa. São os paradoxos, ou melhor, as incoerências que a cultura capitalista provoca.

Quando a mulher utiliza seu corpo como obra e sua obra é inserida na lógica burguesa, ou seja, torna-se mercadoria, o mesmo acontece com seus corpos? Quais são as implicações, em termos conceituais, desse trânsito? No caso de Helena Almeida, em que "a minha obra é o meu corpo, o meu corpo é a minha obra", quais as consequências da capitalização das experiências artísticas contemporâneas em nível da apreciação crítica e do caráter subversivo que carregam?

Obras legitimadas pelo sistema da arte acabam sublimadas de seus contextos revolucionários, entretanto, resistem, na medida que penetram na visualidade contemporânea compartilhada, justamente pelo fato de circularem, estamparem os livros, manuais, revistas, outdoors, etc. conformação de visualidades compartilhadas, referências, etc. Há também o movimento inverso, uma vez que debates contemporâneos impactam nas escolhas feitas pelo sistema de arte, ocasionando novas narrativas para a História da Arte, novas referências para a cultura visual de modo geral e de modo específico, para quem produz, compra, estuda, consome arte. 


\section{Referências}

ALMEIDA, Helena. [Entrevista concedida a] Helena Vasconcelos. Storm Magazine, 23 jun. 2008. Disponível em: http://gfilomenasoares.com/Content/Files/Noticias/Press antigo/8_Storm_Maga zine.pdf. Acesso em: 30 jan. 2020.

ALMEIDA, Helena. Ouve-me. In: CENTRO DE ARTE MODERNA GULBENKIAN. Lisboa: Centro De Arte Moderna Gulbenkian, [20--]. Disponível em: https://gulbenkian.pt /cam/works_cam/ouve-me-145250/. Acesso em: 01 out. 2020.

ALMEIDA, Marta Moreira de; Ribas, João. Helena Almeida: a minha obra é o meu corpo, o meu corpo é a minha obra. Porto: Fundação de Serralves; Paris: Jeu de Paume, Bruxelas: WIELS, 2015.

ARGAN, Giulio Carlo. Arte Moderna. São Paulo: Companhia das Letras, 2010.

BENJAMIN, Walter. Obras escolhidas: magia e técnica, arte e política: ensaios sobre literatura e história da cultura. São Paulo: Brasiliense, 1987. v. 1.

BOURDIEU, Pierre. A Economia das Trocas Simbólicas. São Paulo: Perspectiva, 2013.

GOMES, Filipa; RODRIGUES, Cristiana; MENDONÇA, Ricardo. Helena Almeida: Era uma vez uma mulher sem sombra que encontrou uma. Monografia. Faculdade de Belas Artes: Universidade de Lisboa, 2006.

GUIMARÃES, Patrícia. Sistemas de Arte e o lugar da História. In: ENCONTRO NACIONAL ANPAP, 22., 2013, Belém. Anais [...]. Belém: Ecossistemas Estéticos, 2013. p. 2033-2041.

HADJINICOLAOU, Nicos. Historia del arte y lucha de clases. Madri: Siglo Veintiuno Editores, 1980.

LAURETIS, Tereza de. A tecnologia do gênero. Indiana: Indiana University Press, 1987.

MARX, Karl; ENGELS, Friederich. Manifesto do Partido Comunista. São Paulo: LP\&M Editora, 2001.

MIRA, Rita. Helena Almeida: a minha obra é o meu corpo, o meu corpo é a minha obra. In: FACES DE EVA: estudos sobre a mulher. Lisboa, n. 35, 2012. p. 221-224. 
MORAIS, Paula. Portugal sob a égide da ditadura: o rosto metamorfoseado das palavras. Lisboa: Chiado Editora, 2014.

NOCHLIN, Linda. Por que não houve grandes mulheres artistas? São Paulo: Edições Aurora, 2016.

OLIVEIRA, Márcia. Arte e feminismo em Portugal no contexto pós-revolucionário. Ribeirão: Edições Húmus, 2015.

POLLOCK, Griselda. Vision and difference: feminism, femininity and histories of art. London: Routledge Classic Editions, 2008.

SPIVAK, Gayatri Chakravorty. Pode o subalterno falar? Belo Horizonte: Editora UFMG, 2010.

WOOLF, Virgínia. Um teto todo seu. São Paulo: Tordesilhas, 2014.

Recebido em: 21/03/2021 Aprovado em: 18/10/2021

Universidade do Estado de Santa Catarina - UDESC Centro de Ciências Humanas e da Educação - FAED

PerCursos

Volume 22 - Número 50 - Ano 2021 revistapercursos@gmail.com 